\title{
Arterial Performance Measures Re-Identification Software Demonstration
}
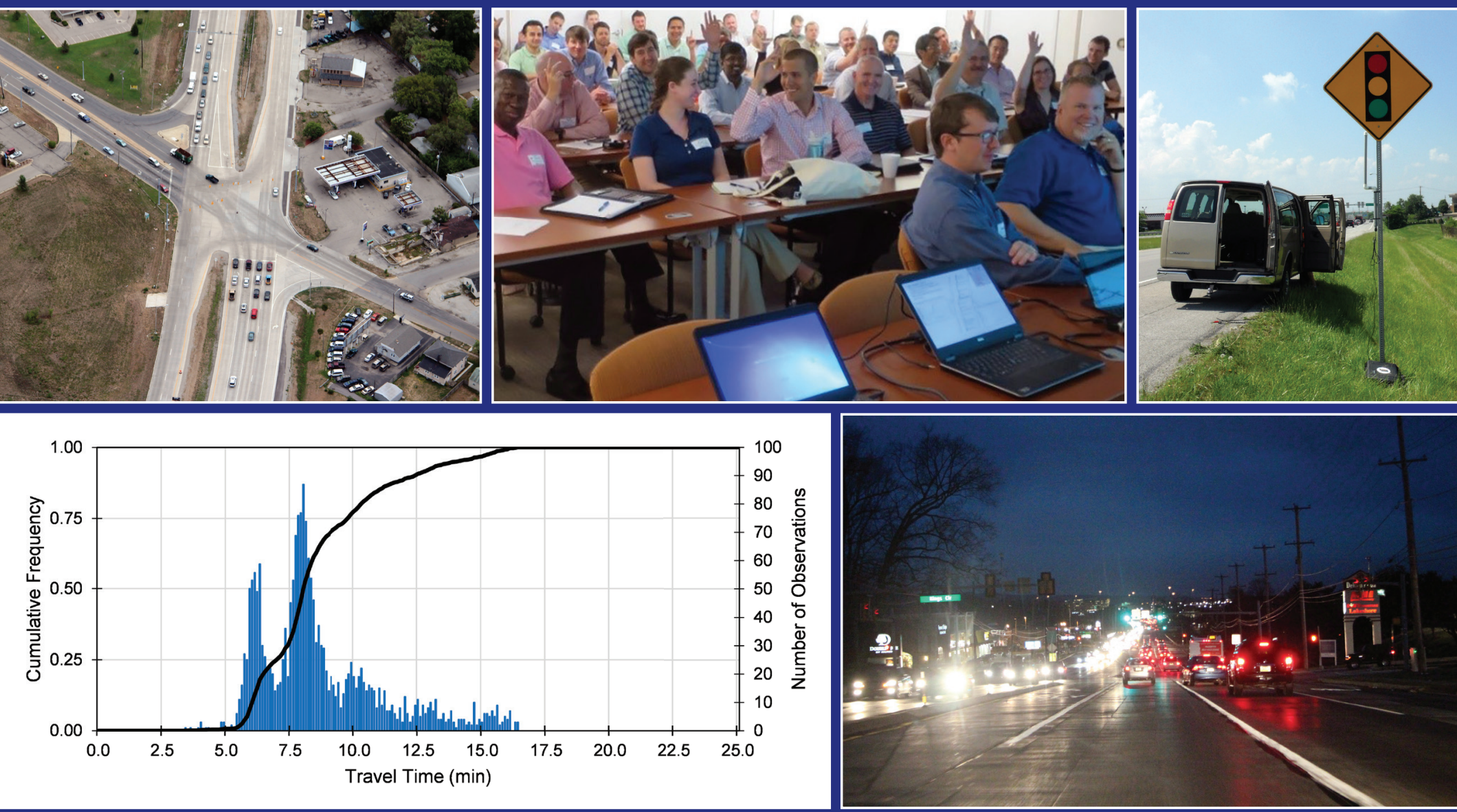

Stanley E. Young, Dennis So Ting Fong 


\title{
Arterial Performance Measures Re-Identification Software Demonstration
}

\author{
Stanley E. Young \\ Traffax, Inc. \\ Dennis So Ting Fong \\ Traffax, Inc.
}

\begin{abstract}
SBIR Phase 3 Joint Transportation Research Project
Traffax, Inc.

Purdue University
\end{abstract}

June 2, 2017

\begin{tabular}{|l|l|}
\hline Deliverable Reference: & D2.4 Software Demonstration \\
\hline Contractor: & Traffax, Inc. \\
\hline Contract Number: & DTFH61-14-C-00035 \\
\hline Contract Term Start & $9 / 4 / 2014$ \\
\hline Contract Term End & $9 / 4 / 2017$ \\
\hline Key Personnel & Stan Young, Darcy Bullock, Dennis So Ting Fong \\
\hline
\end{tabular}




\section{Recommended Citation}

Young, S. E., and D. S. T. Fong. Arterial Performance Measures Re-Identification Software Demonstration. Purdue University, West Lafayette, Indiana, 2017. https://doi.org/10.5703/1288284316568

\section{Acknowledgments}

This work was supported by Traffax/USDOT SBIR DTFH6114C00035. The contents of this paper reflect the views of the authors, who are responsible for the facts and the accuracy of the data presented herein, and do not necessarily reflect the official views or policies of the sponsoring organizations. These contents do not constitute a standard, specification, or regulation. 


\section{Presentation Description}

A recorded demonstration was prepared explaining the purpose, development, framework, and potential uses of the developed open-source software described in the previous reports entitled, "Arterial Performance Measures Software” dated February 13, 2017, "Arterial Network Performance Measures Software” dated April 4, 2017, and “Arterial Trip Length Characteristics Software” dated June 30, 2017. The recorded presentation can be viewed at:

https://webmeeting.umd.edu/p3c5ymxjq97/?OWASP_CSRFTOKEN=e1c84f4446075128a4ceb0 979ccc05c3c12da7eb212a4f14ca957d2e11c4514c

The PowerPoint slide deck included with this deliverable and all of the project reports can be accessed at: https://tinyurl.com/ydz7dm3j. 


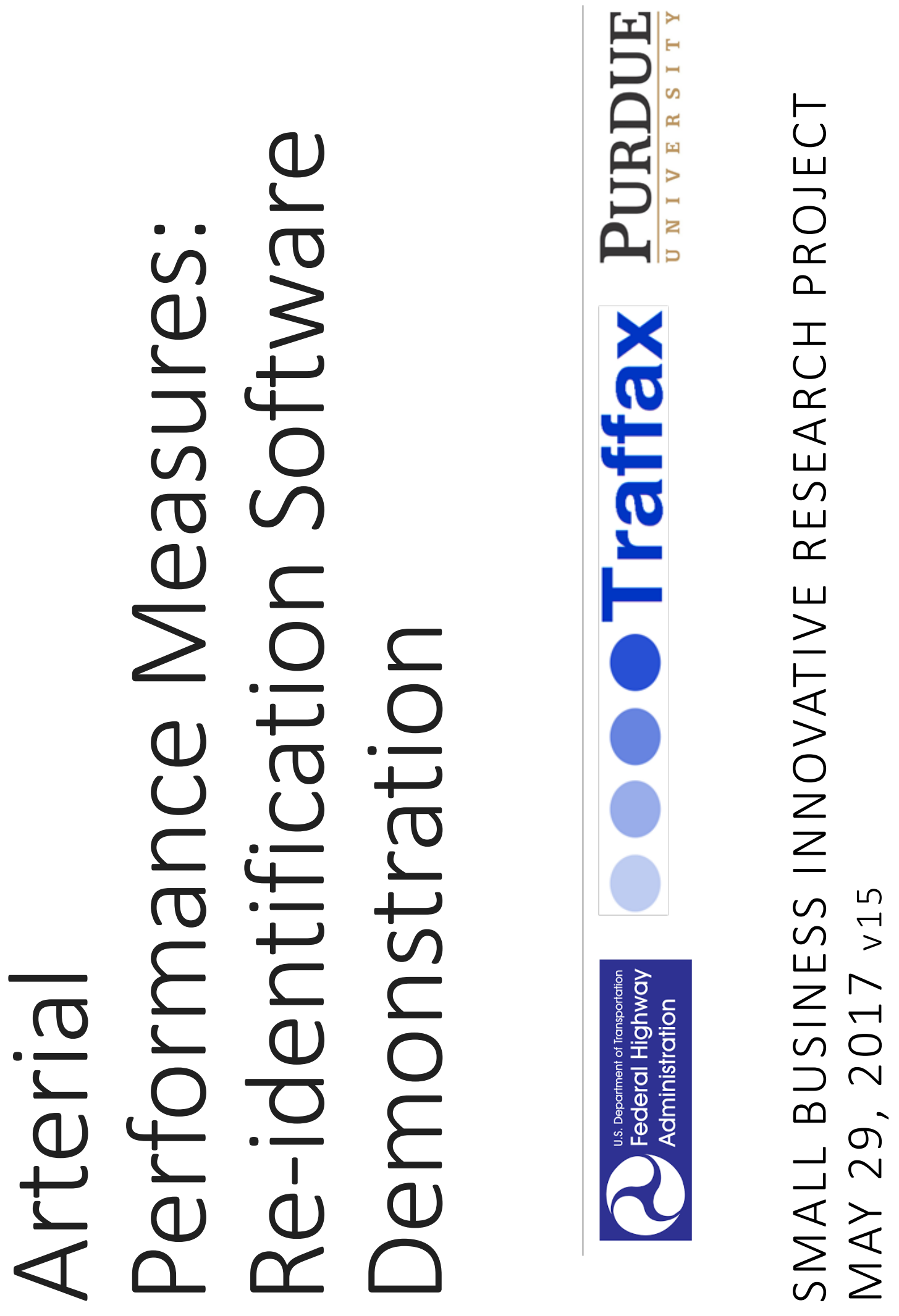




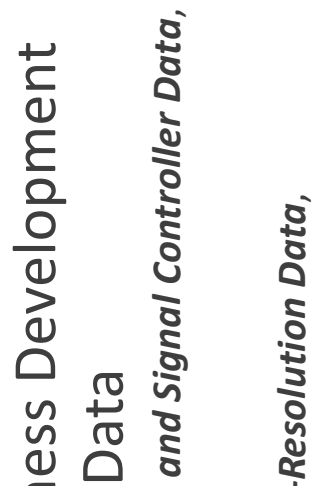

¿

(U) 

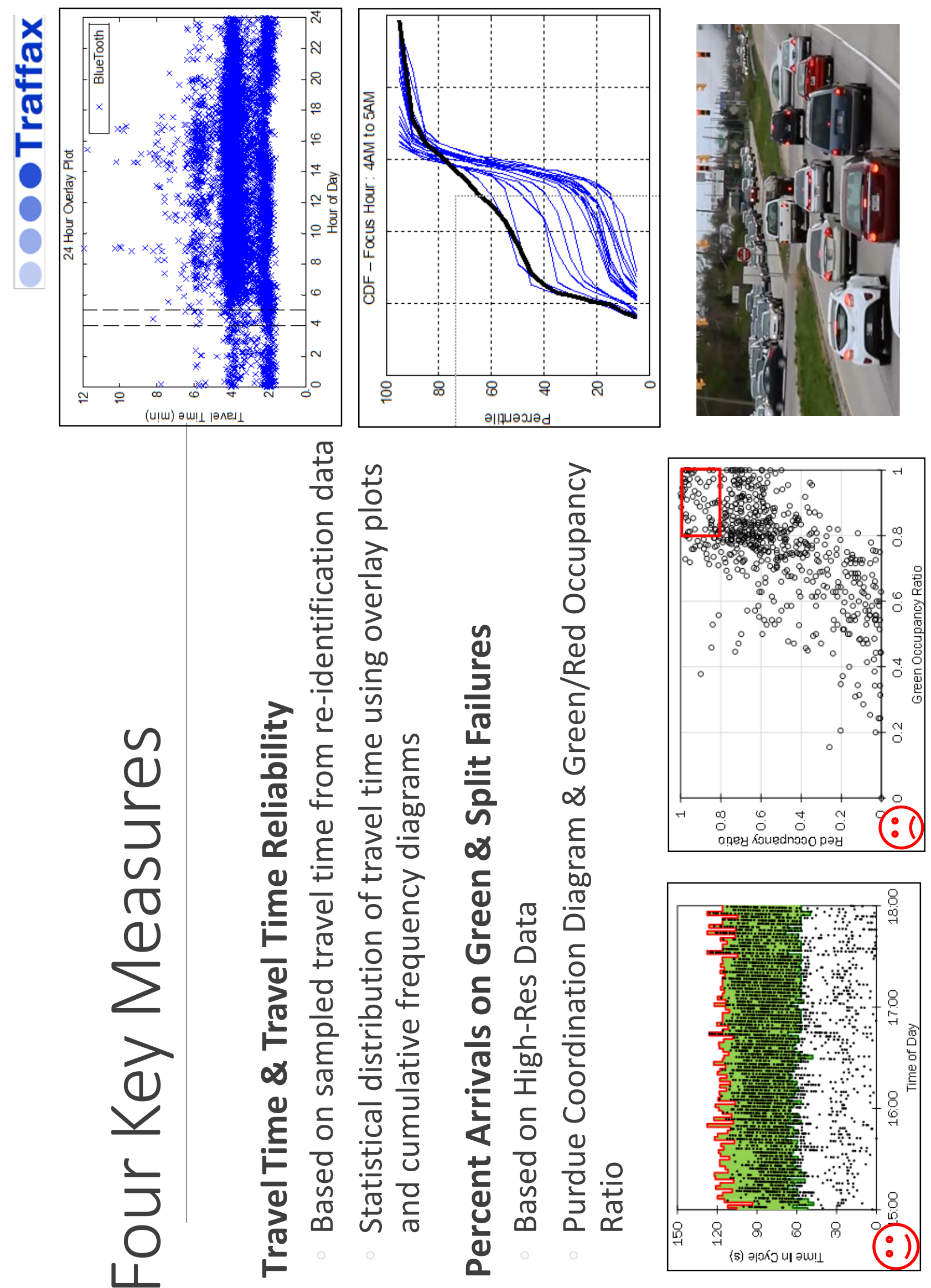


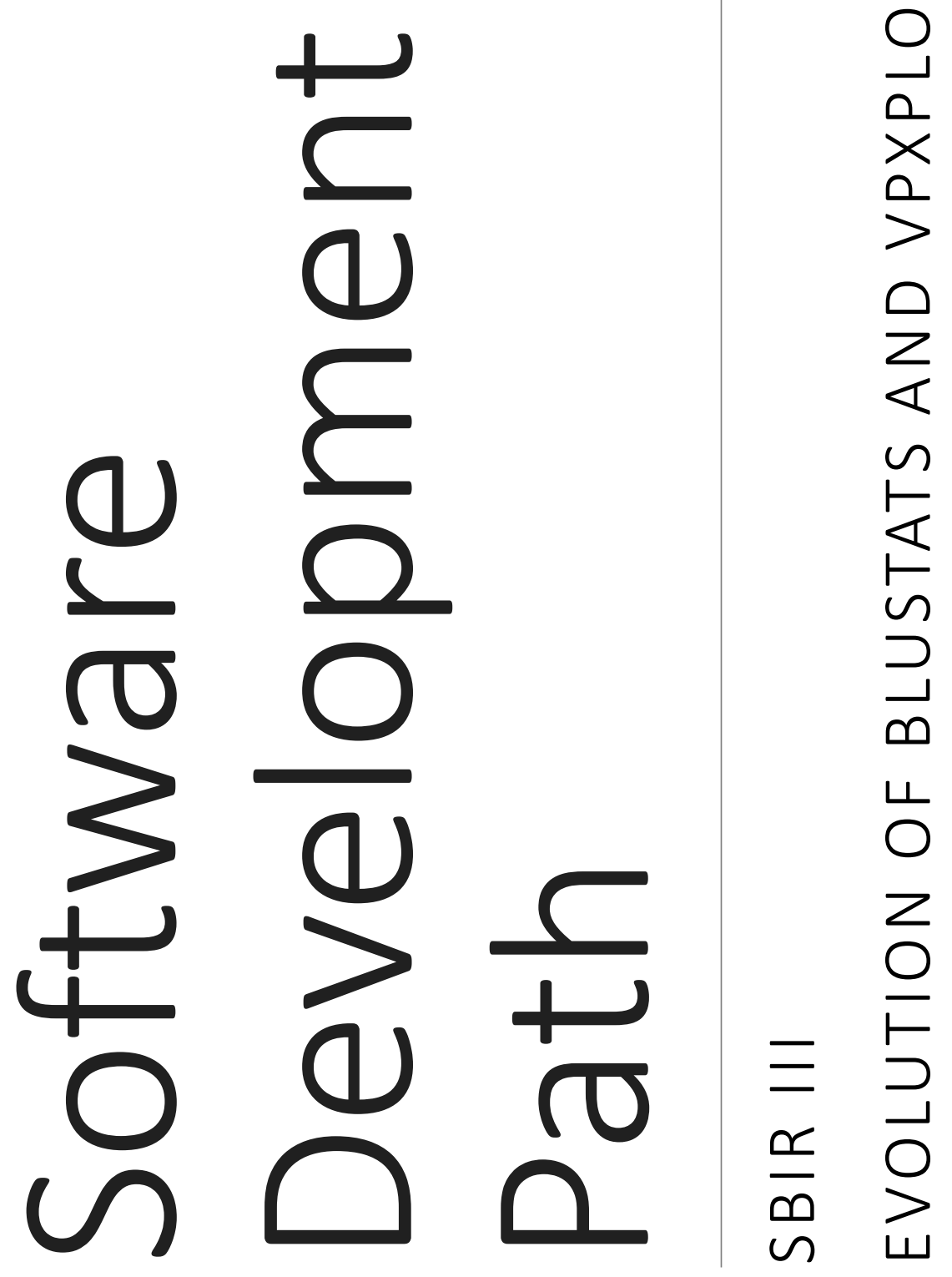




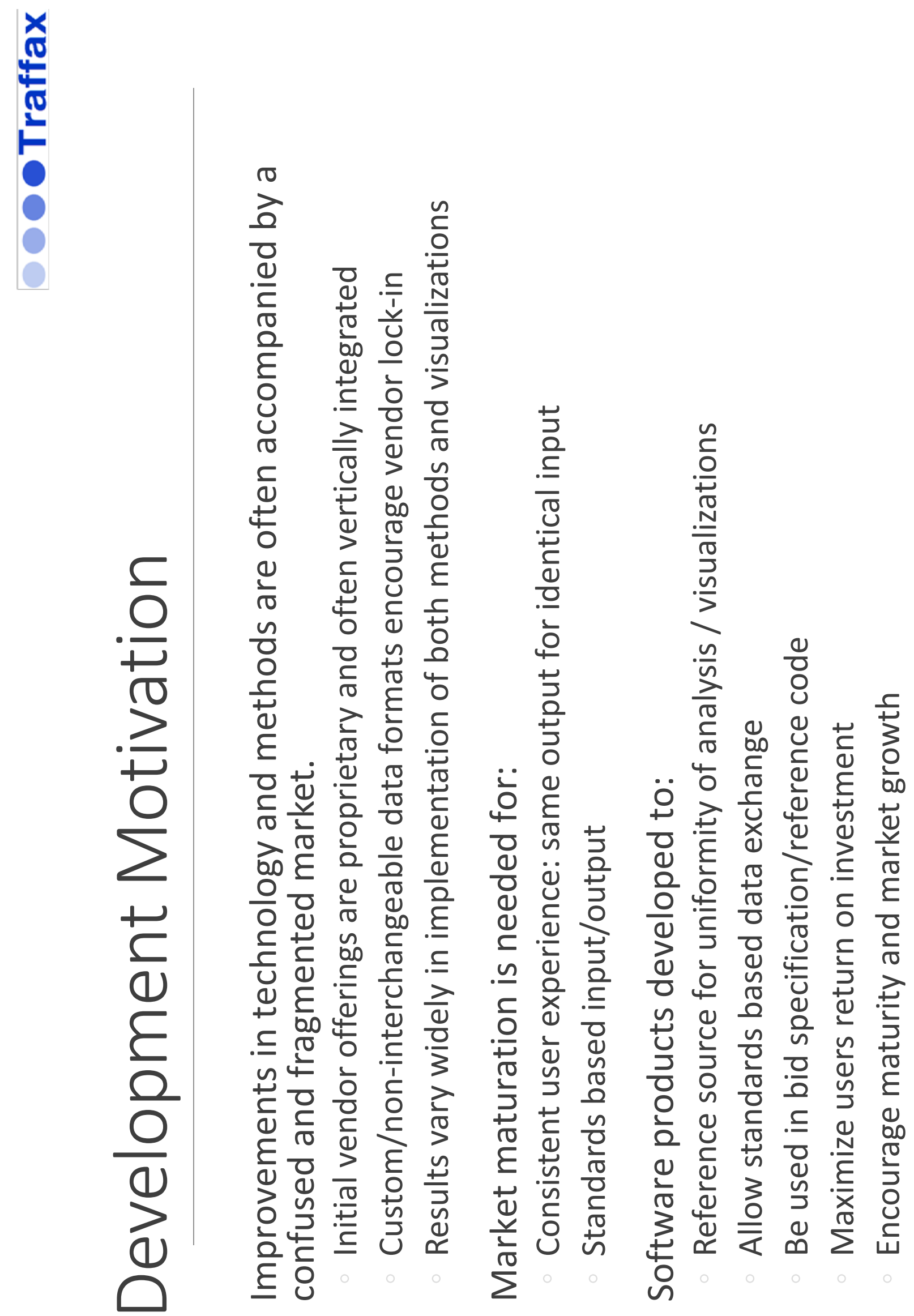



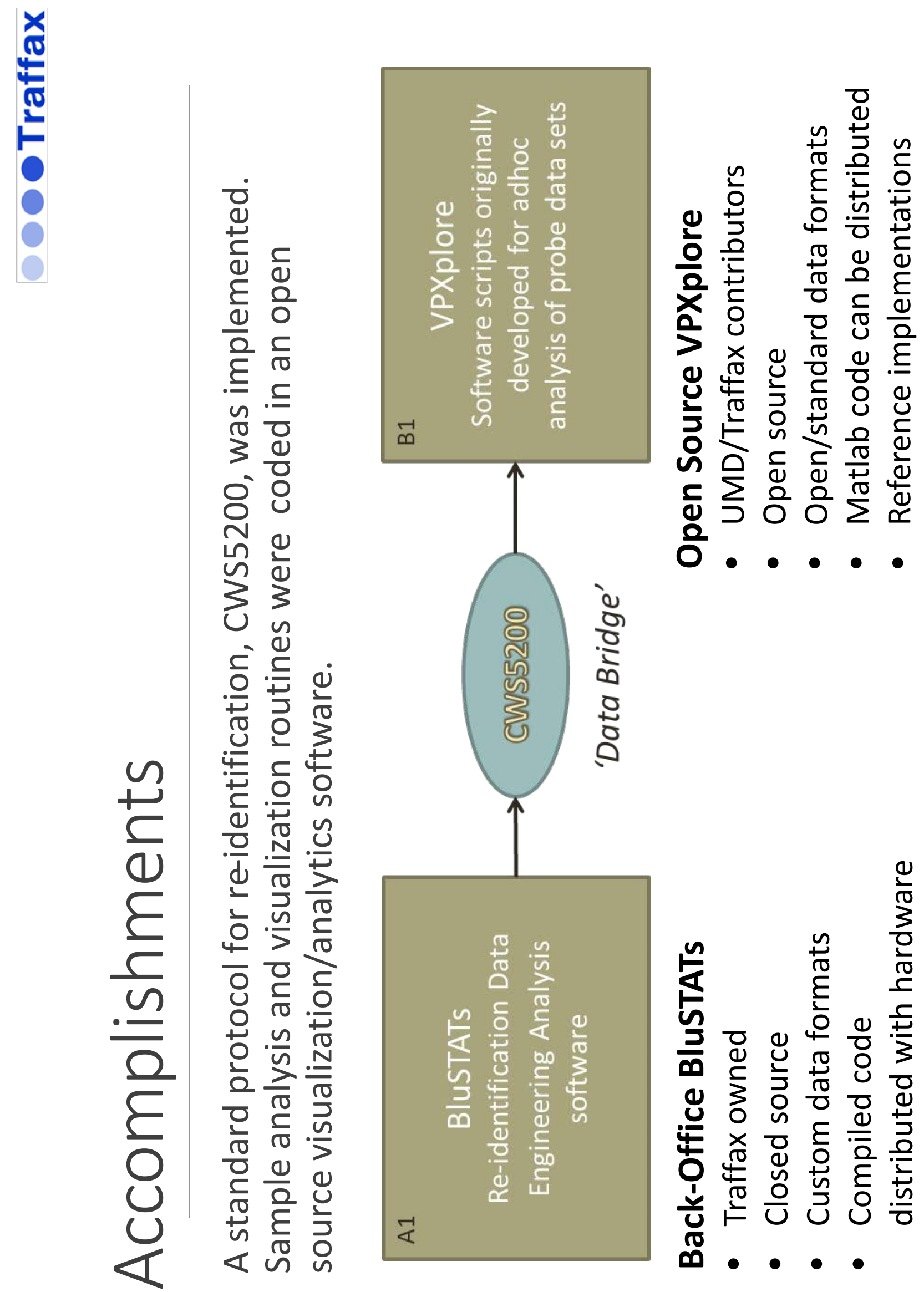


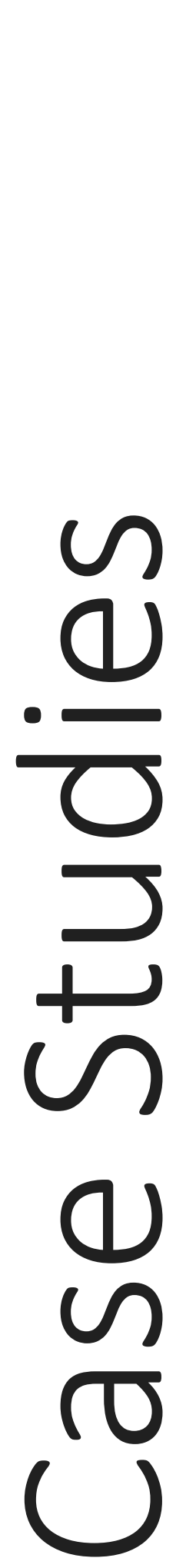




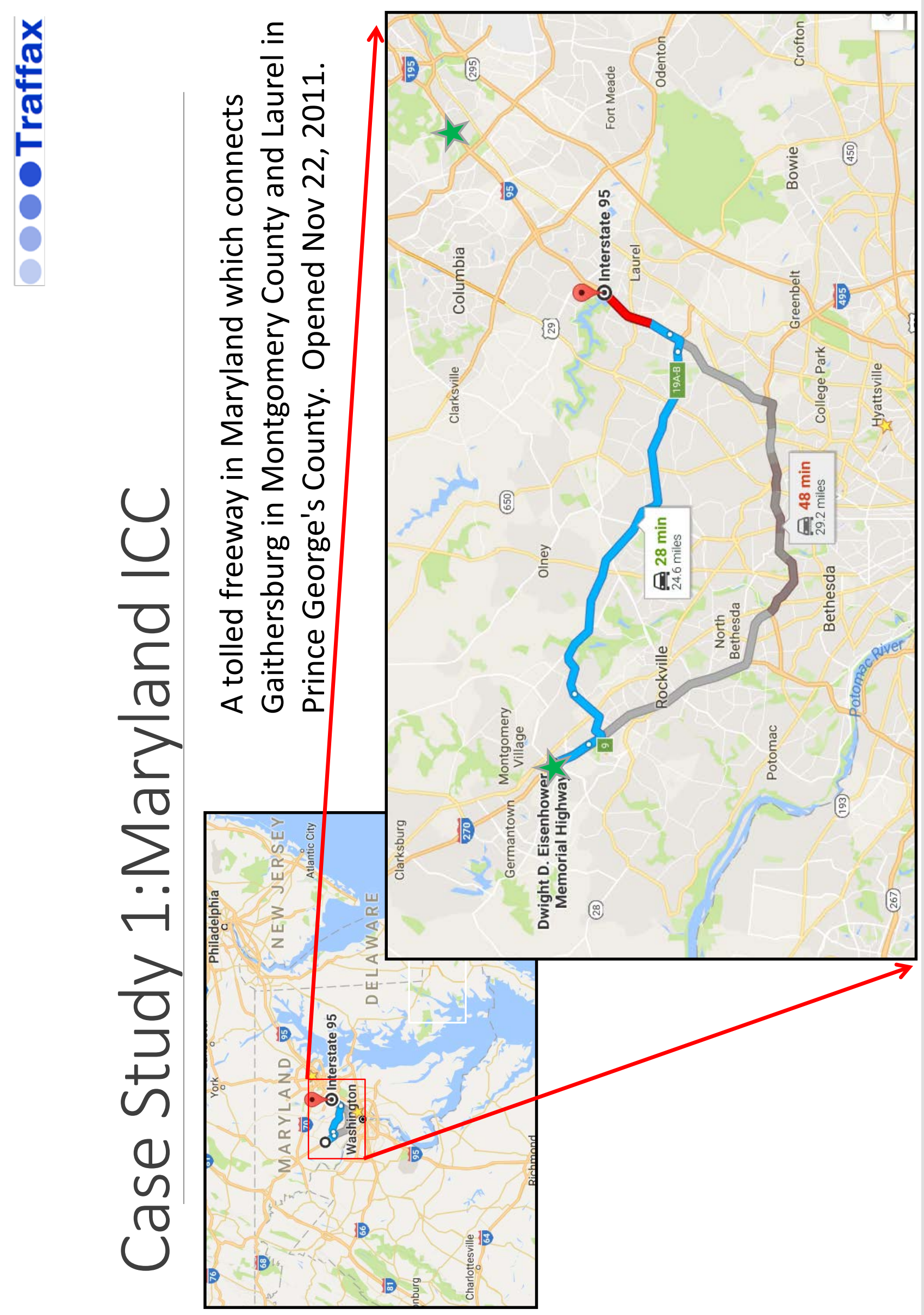




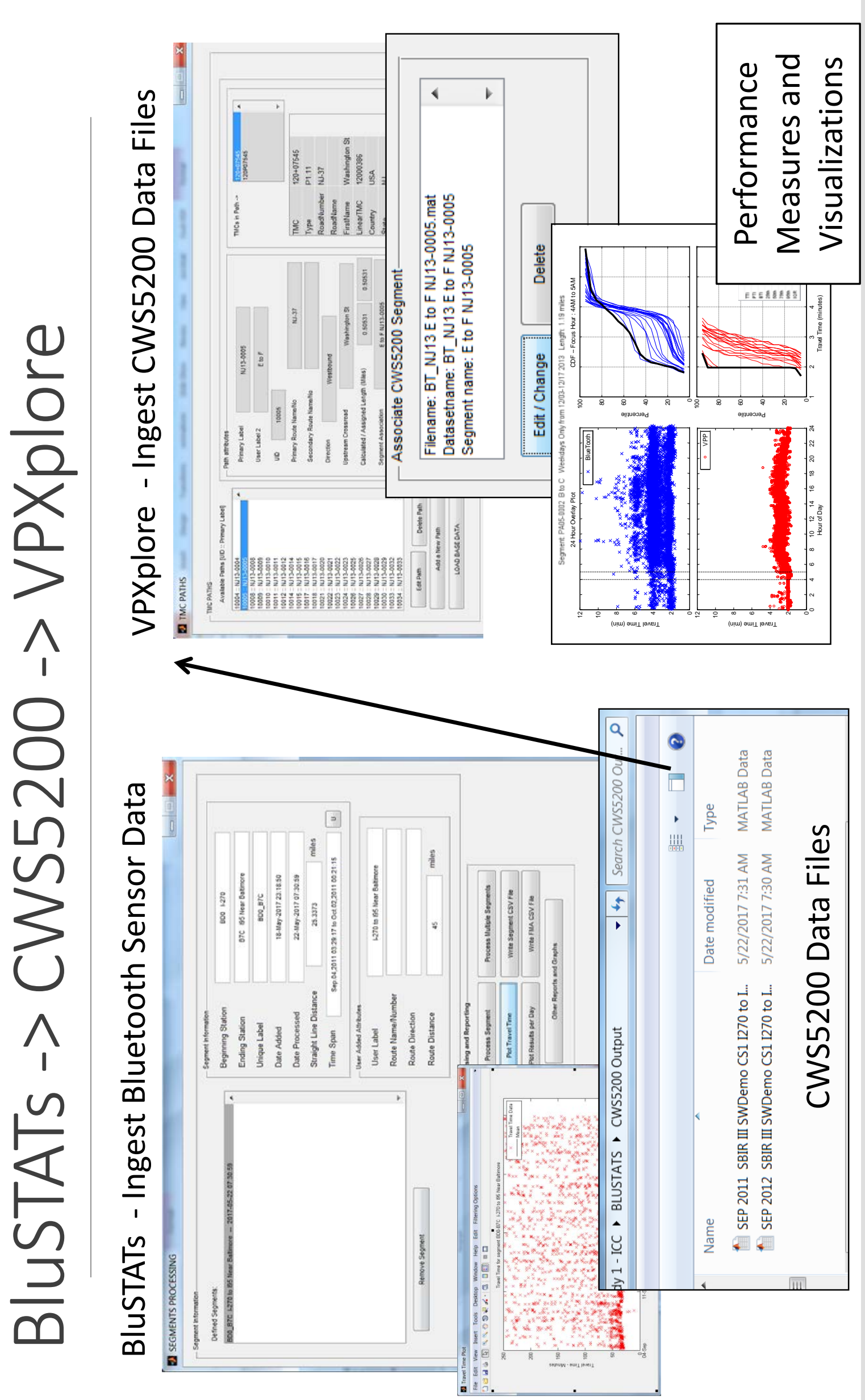



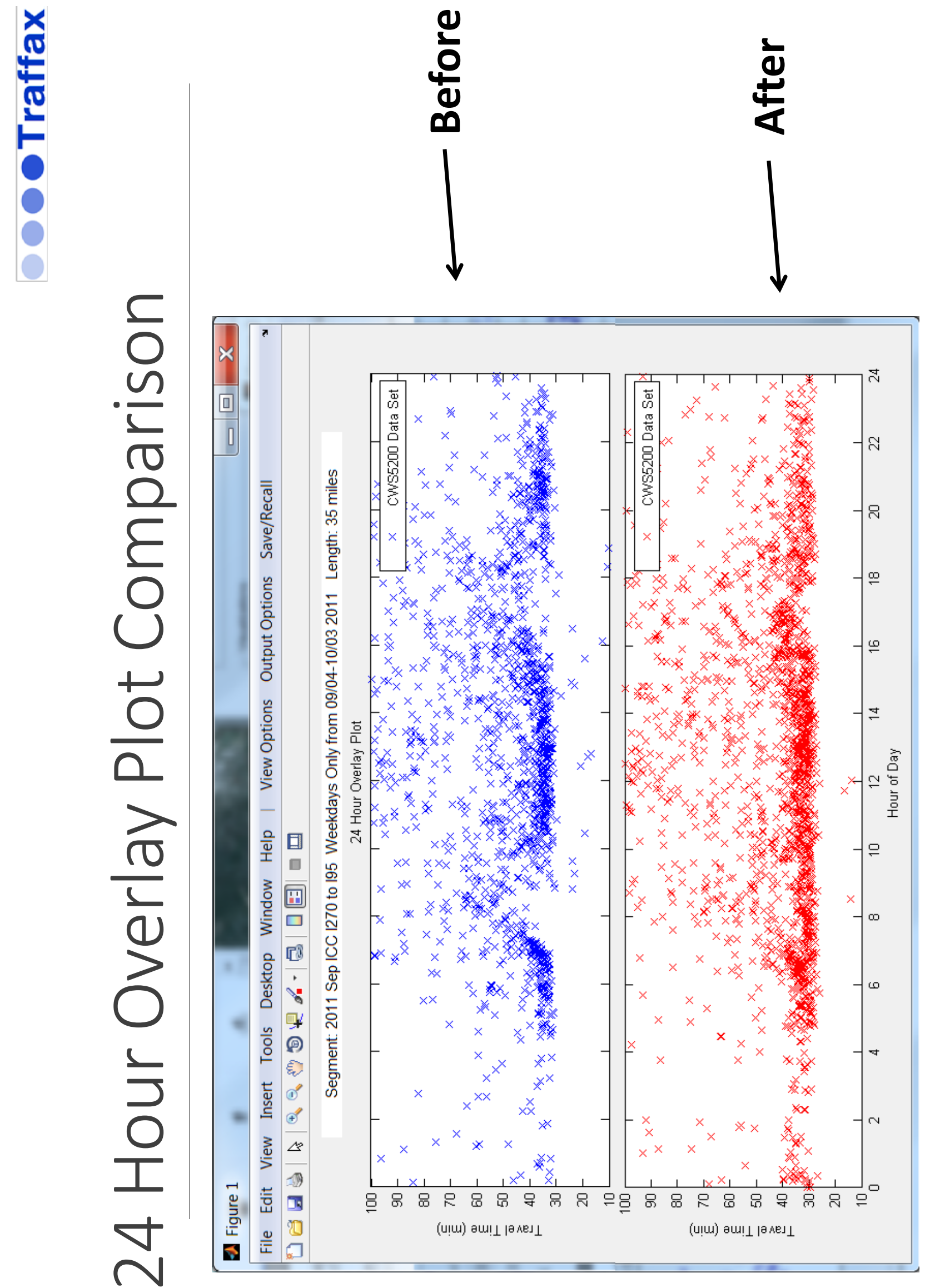

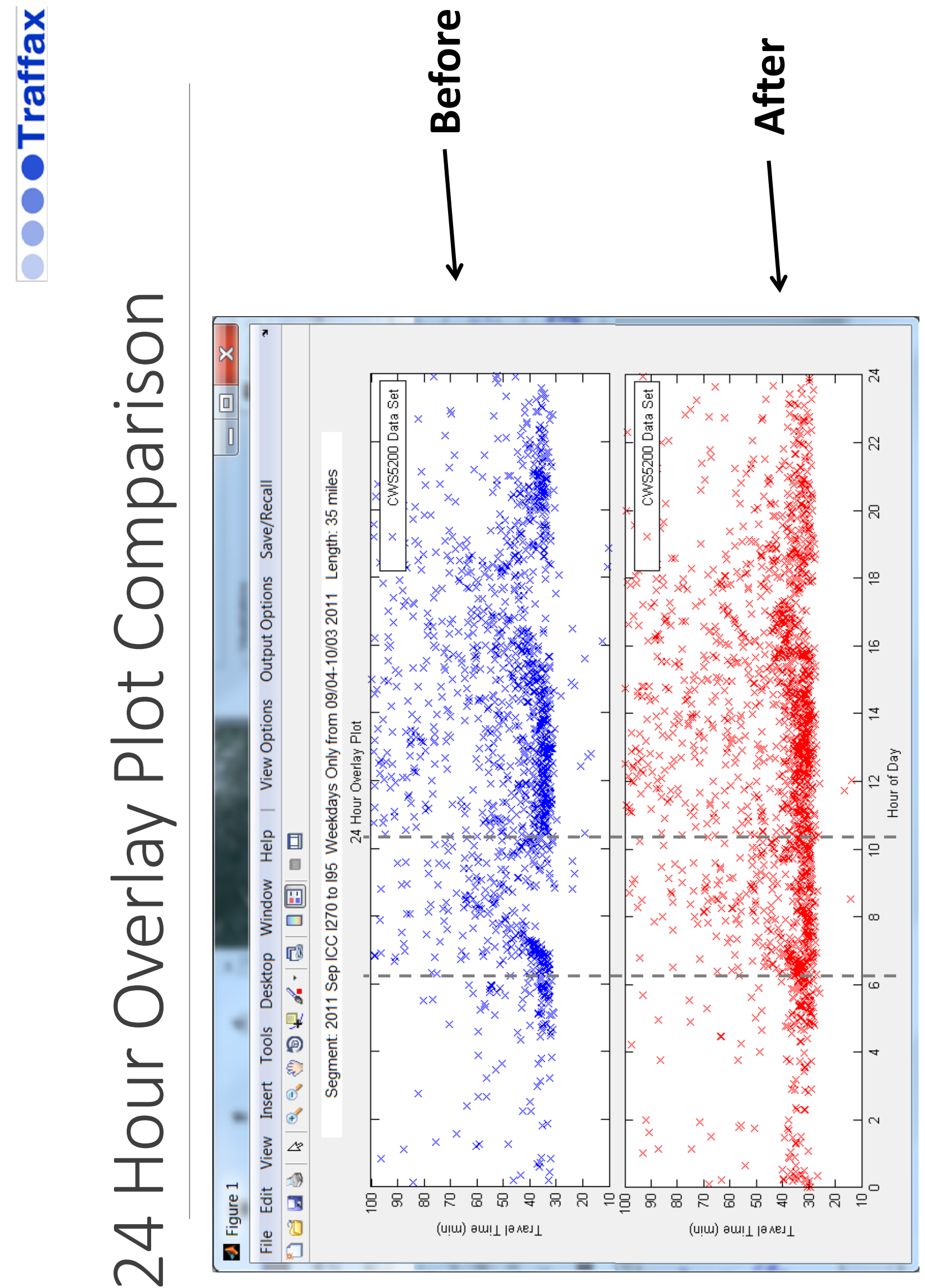


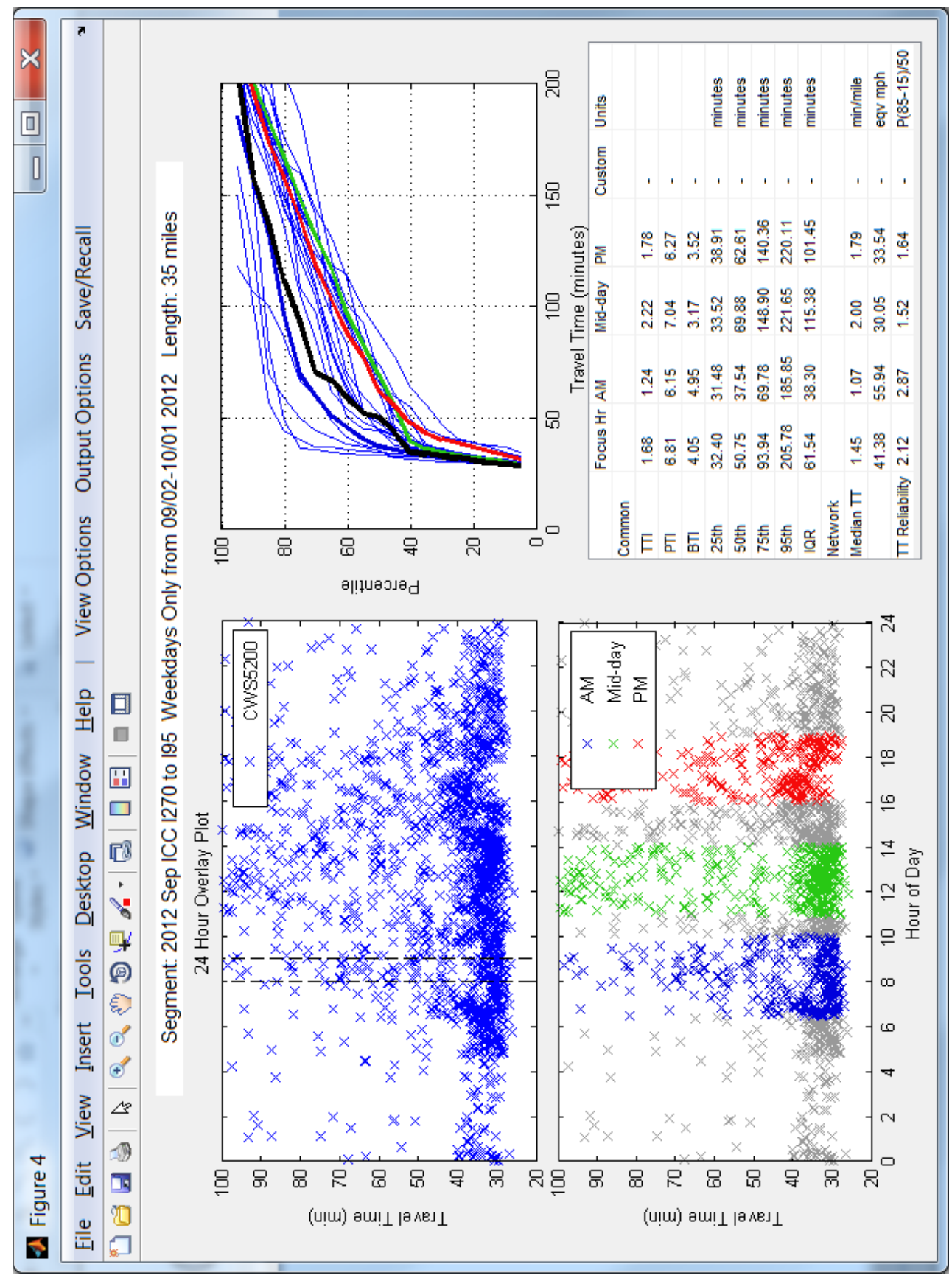




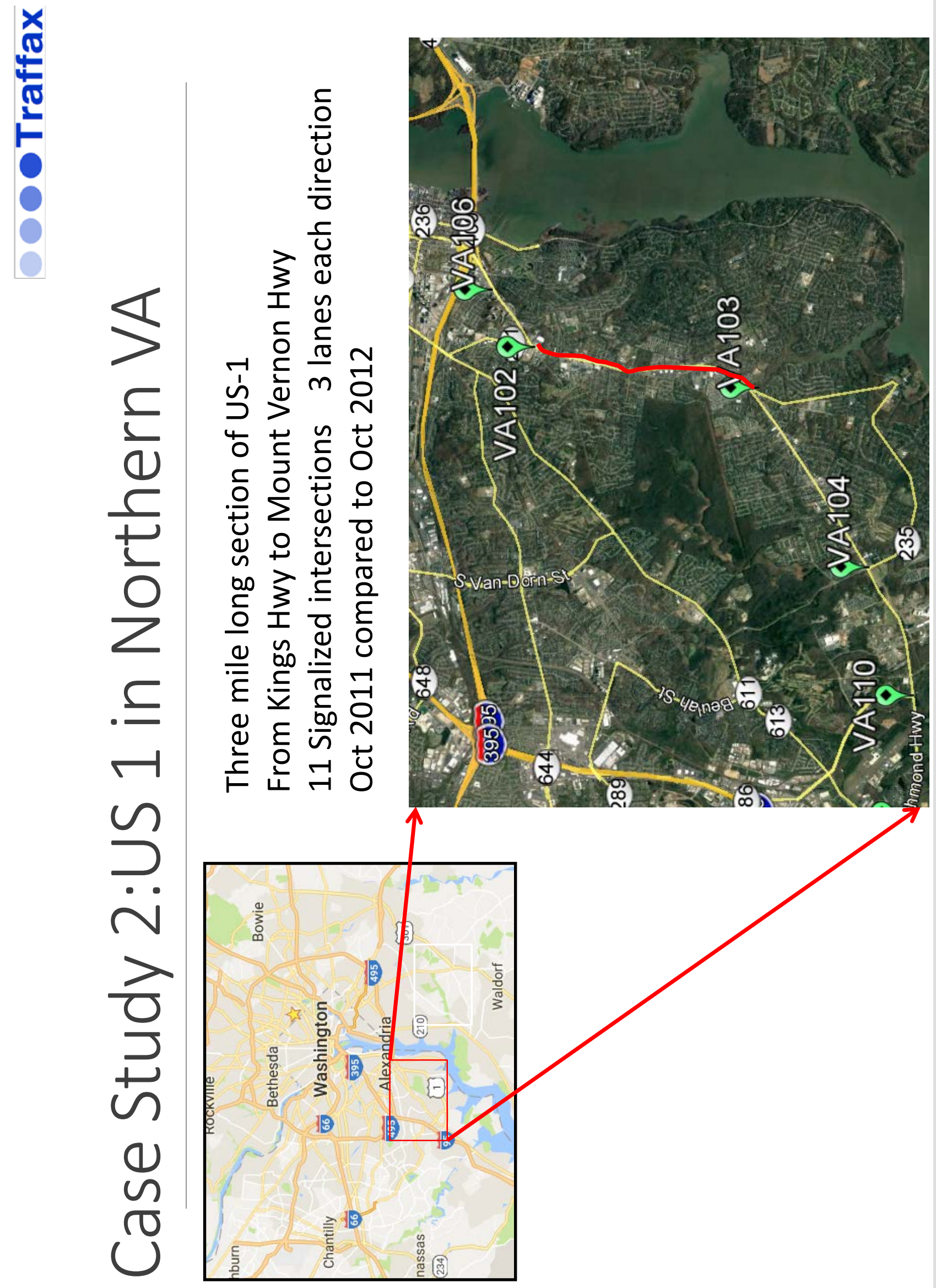



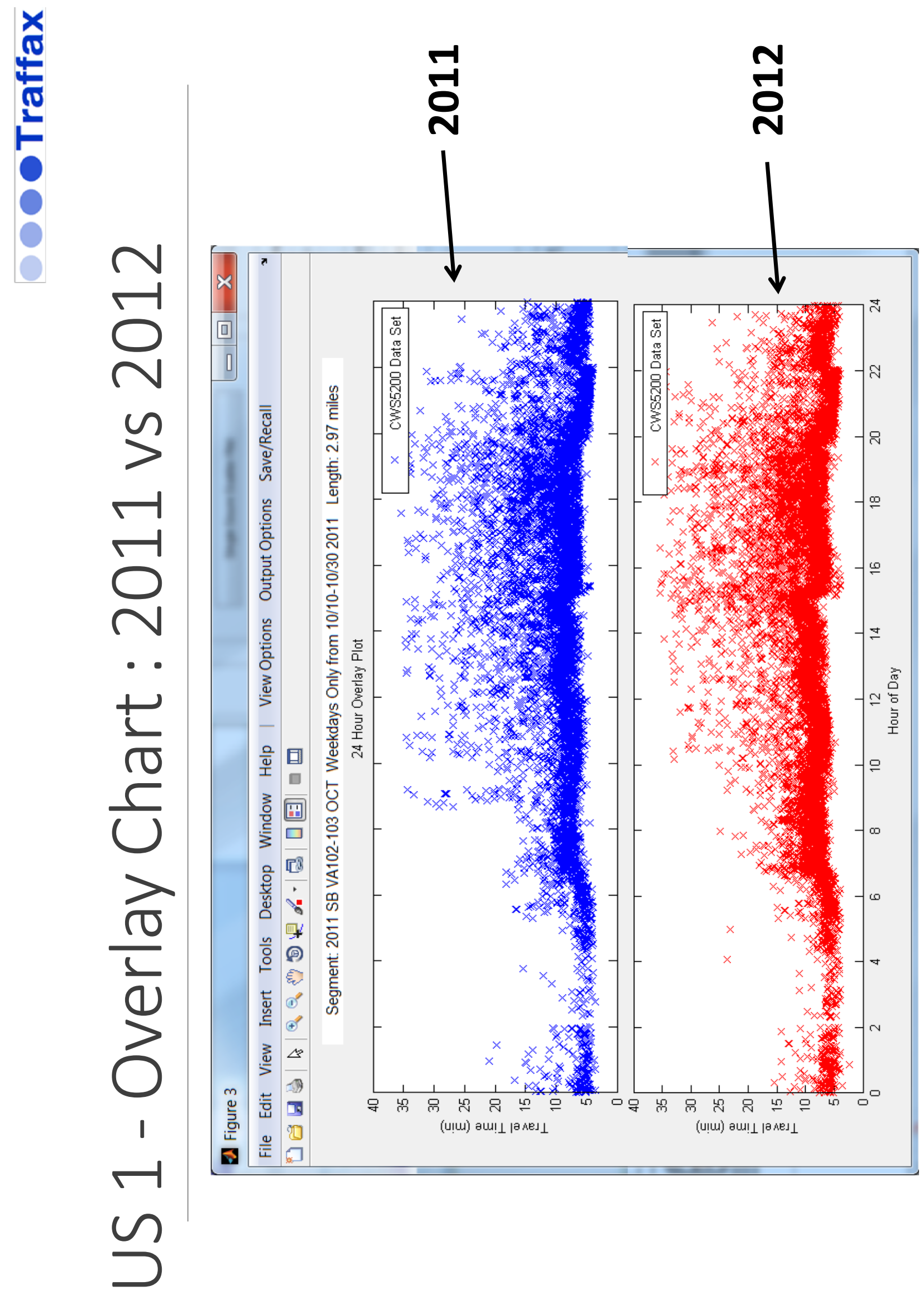


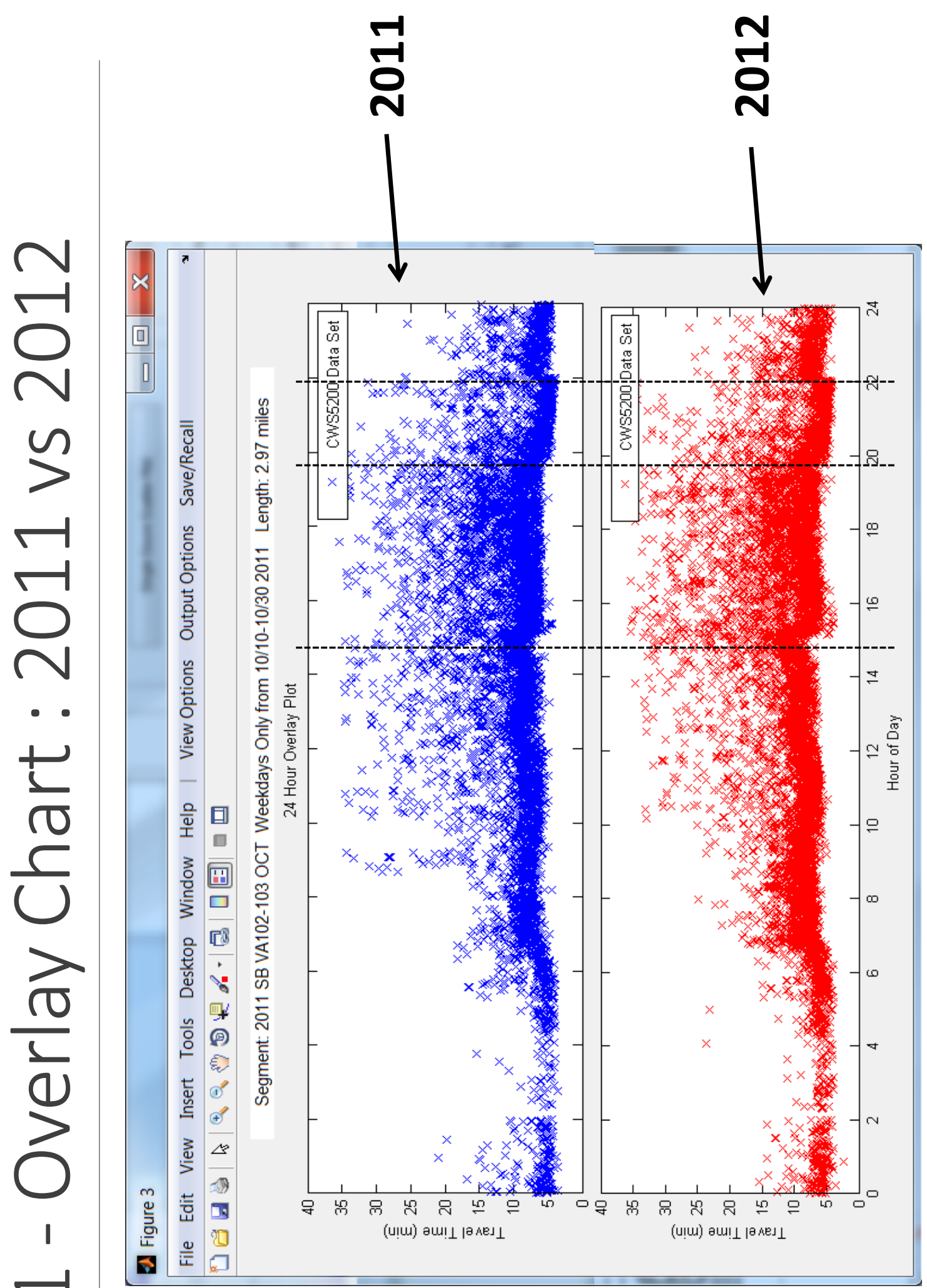




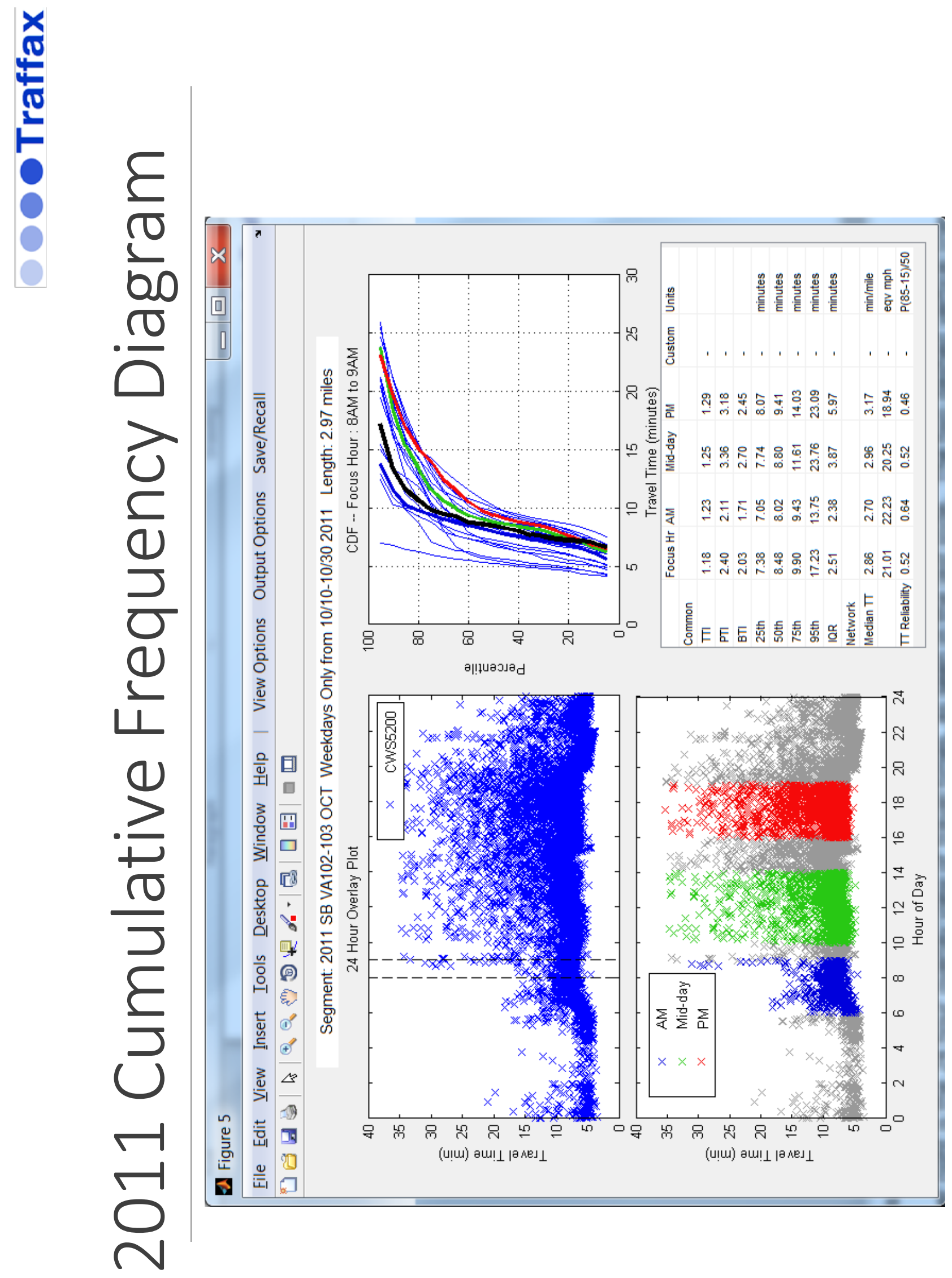




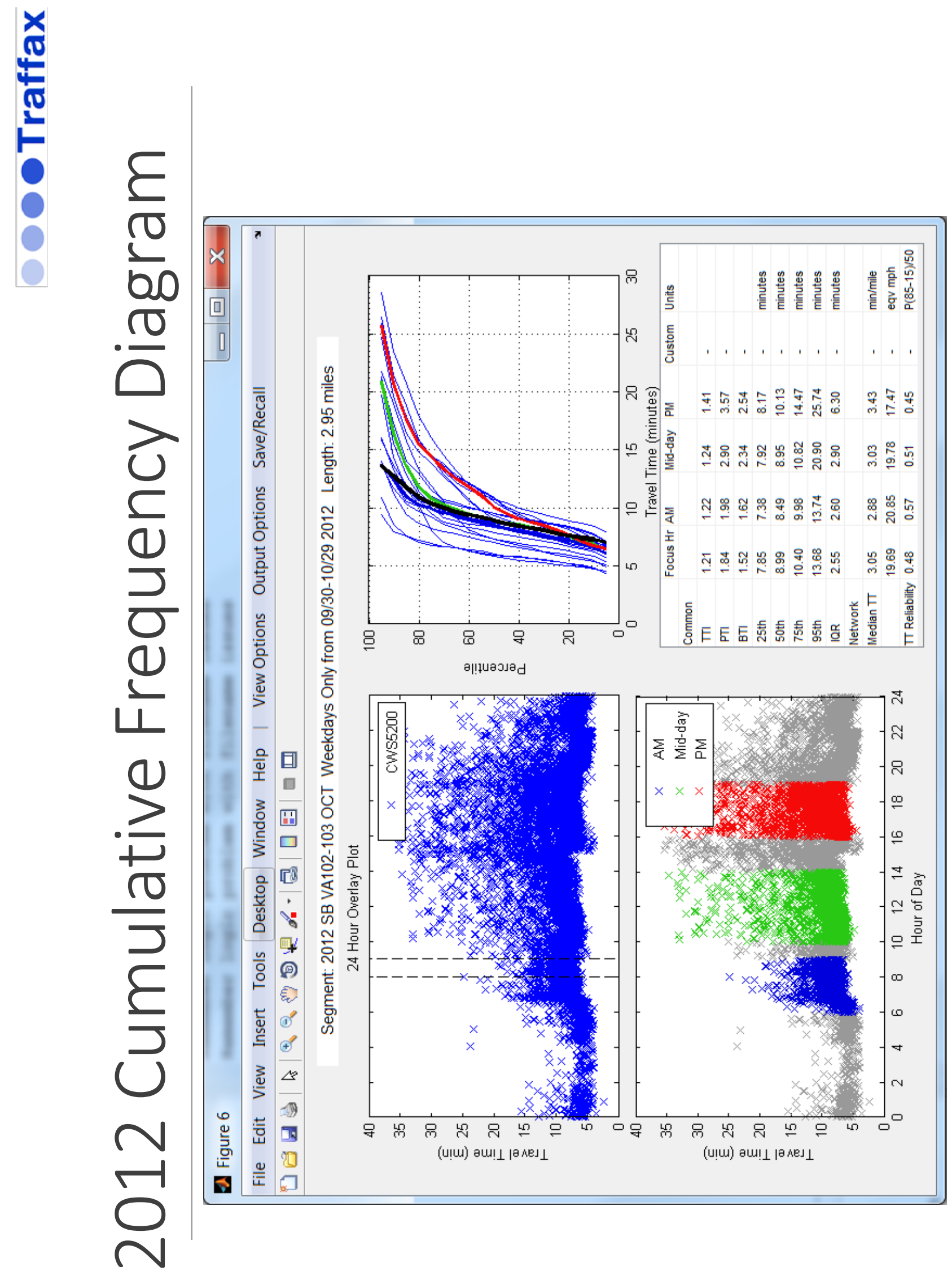




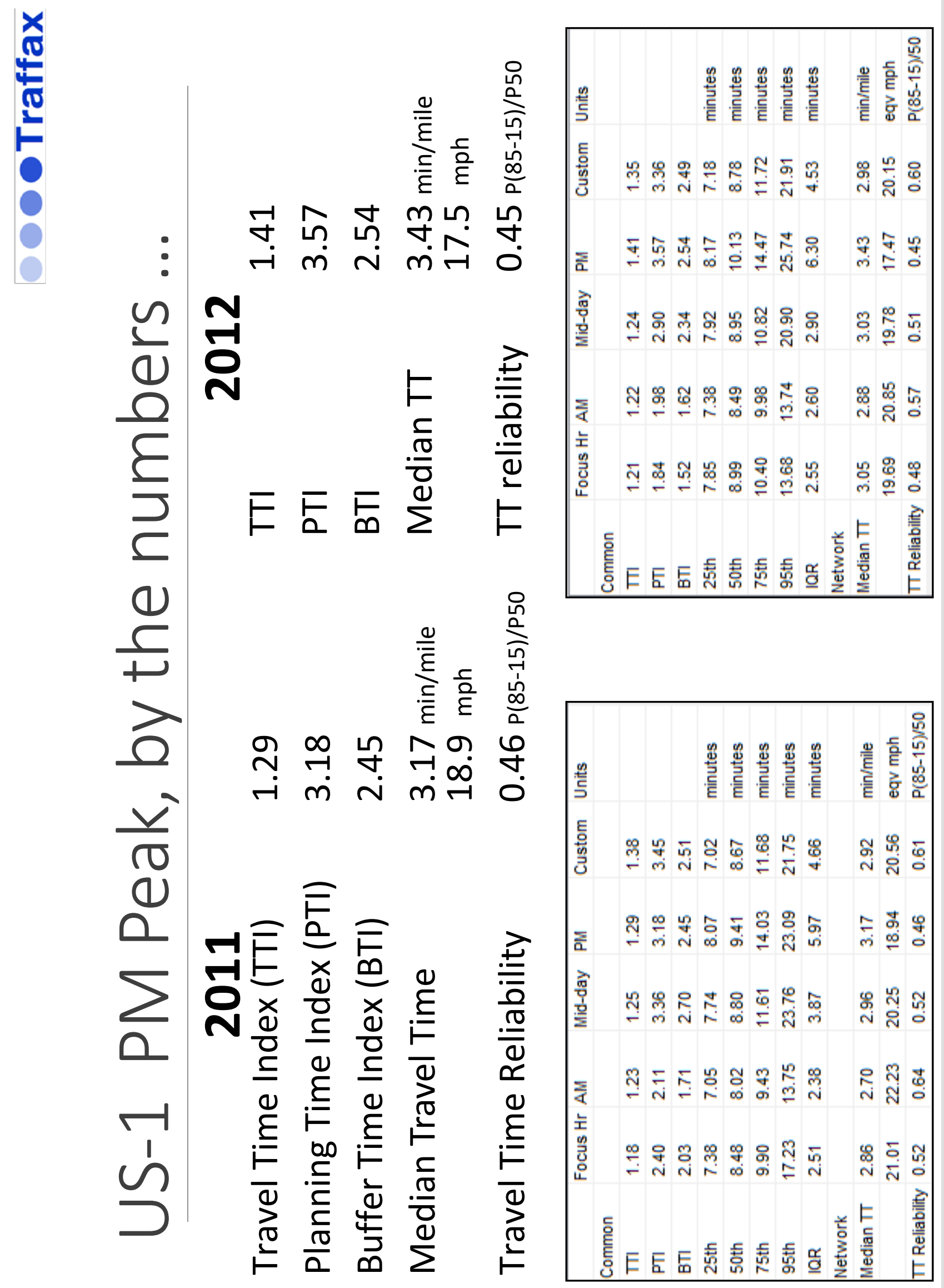




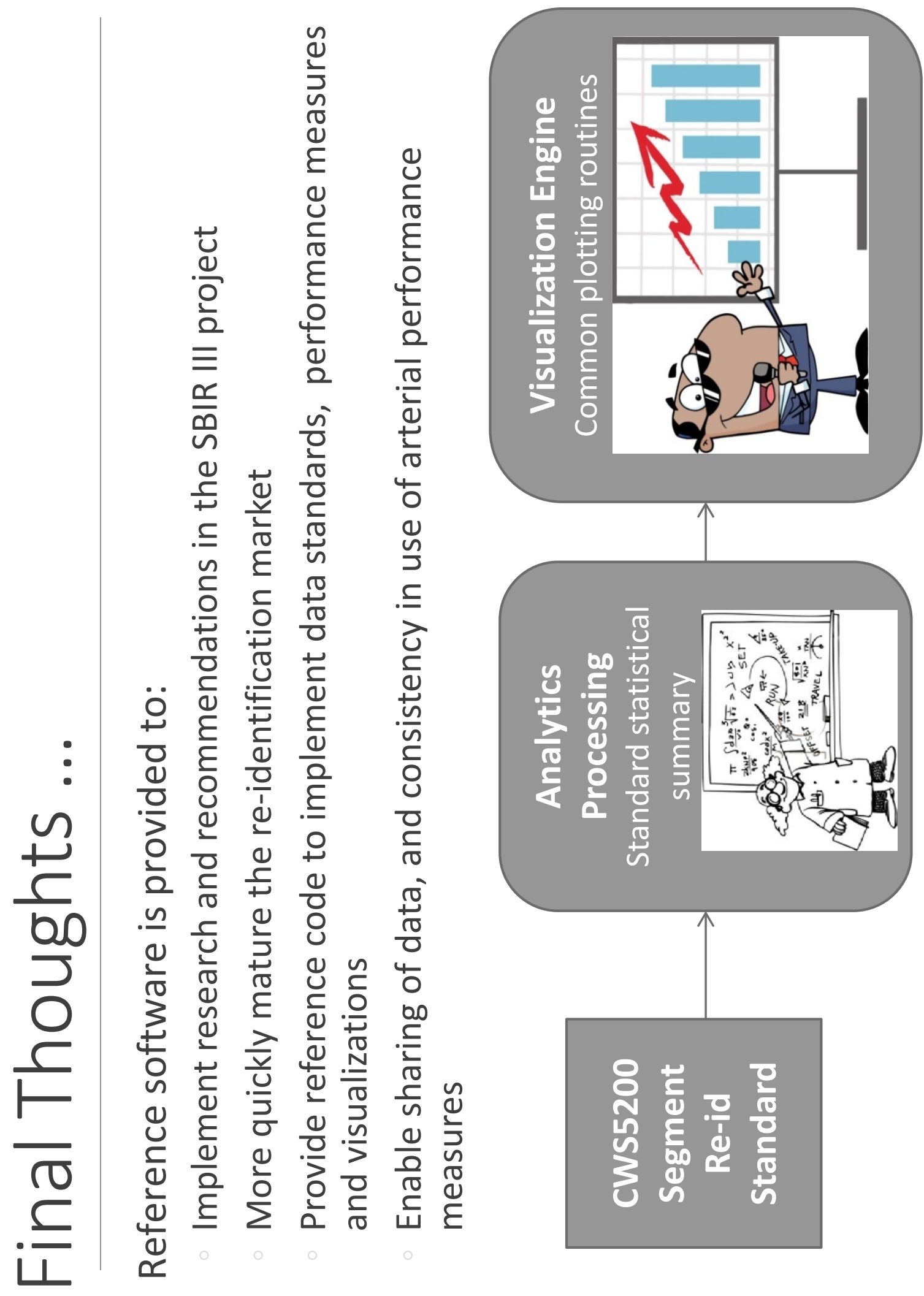


10

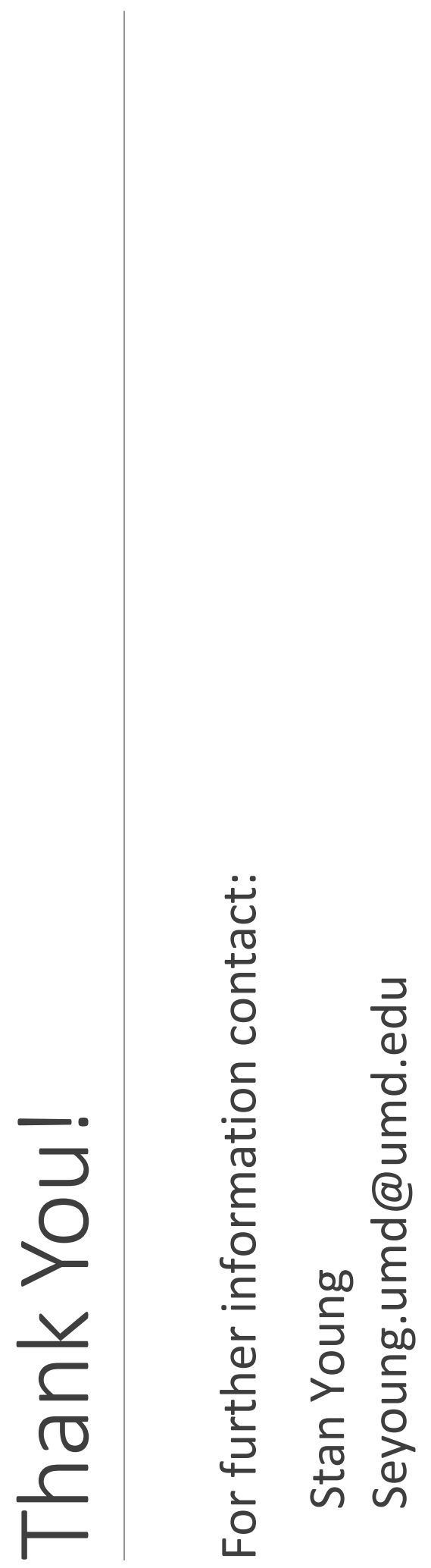




\section{Report Sponsor}

The "Small Business Innovation Development Act of 1982" (Pub. L. No. 97-219), along with reauthorizing legislation (Pub. L. No. 99-443 and Pub. L. No. 102-564, the "Small Business Research and Development Enhancement Act of 1992"), seeks to encourage the initiative of the private sector and to use small business effectively to meet federal research and development objectives. To comply with statutory obligations of the Act, the U.S. Department of Transportation established the Small Business Innovation Research (SBIR) Program, which conforms to the guidelines and regulations provided by the Small Business Administration. Annually, small businesses are solicited to submit innovative research proposals that address the high-priority requirements of the U.S. Department of Transportation and that have potential for commercialization.

This report was developed through a partnership between Traffax, Inc., and Purdue University with funding from a Phase III SBIR contract (DTFH6114C00035) with the Federal Highway Administration. The project, entitled "Sensor Fusion and MOE Development for Off-Line Traffic Analysis of Real Time Data," created and refined methods and tools for the characterization of performance along arterial corridors.

\section{Publication}

This report is part of a series of reports published in collaboration with USDOT, Traffax, Inc., and Purdue University. The full report series is available for download at http://docs.lib.purdue .edu/apmtp/.

\section{Open Access and Collaboration with Purdue University}

The Indiana legislature established the Joint Highway Research Project in 1937. In 1997, this collaborative venture between the Indiana Department of Transportation and Purdue University was renamed as the Joint Transportation Research Program (JTRP) to reflect state and national efforts to integrate the management and operation of various transportation modes. Since 1937, the JTRP program has published over 1,600 technical reports. In 2010, the JTRP partnered with the Purdue University Libraries to incorporate these technical reports in the University's open access digital repository and to develop production processes for rapidly disseminating new research reports via this repository. Affiliated publications have also recently been added to the collection. As of 2017, the JTRP collection had over 1.5 million downloads, with some particularly popular reports having over 20,000 downloads. 